\title{
Detection of Foreclosure-related Landscape Management Changes Using Landsat
}

Michael Minn ${ }^{\text {a }}$, Bethany B. Cutts* a , Jonathan A. Greenberg ${ }^{\mathrm{b}}$, Nathan Pavlovic ${ }^{\mathrm{b}}$, Jennifer M. Fraterrigo $^{\text {a }}$, V. Kelly Turner ${ }^{c}$

26 April 2015

${ }^{a}$ Department of Natural Resources and Environmental Sciences, University of Illinois UrbanaChampaign

${ }^{\mathrm{b}}$ Department of Geography and Geographic Information Science, University of Illinois at Urbana-Champaign

${ }^{\mathrm{c}}$ Department of Geography, Kent State University

* Corresponding Author: bcutts@illinois.edu (Bethany B. Cutts) 


\begin{abstract}
The volume of properties affected by foreclosure over the past decade suggests the potential for dramatic change in vegetation cover due to changes in management. Yet, the specific pathology of each foreclosure, the temporal asynchrony among foreclosures, and differences in the area available for vegetation growth across properties presents challenges to observing and measuring change. This paper develops and tests a difference in deviations approach that compares the parcel NDVI to a neighborhood norm before and after foreclosure. The difference in deviations approach addresses the challenges of separating parcel-level change corresponding to foreclosure and identifies changes on both small and large parcels. The method relies on a time series of Landsat Normalized Difference Vegetation Index (NDVI) data, individual home foreclosure records and property tax assessment data for Maricopa County, Arizona from 2002-2012. To establish the level of difference associated with observable landscape change, we use a probit regression model, coding Google Earth images for properties across the range of observed deviations of difference. The basic assumption underlying the approach is that if foreclosure coincides with a change in management, it will lead to changes in vegetation structure and thus, NDVI values. We estimate that $13 \%$ of home foreclosures in Maricopa County over the period from 2002-2012 resulted in declines in vegetation whereas $6.5 \%$ resulted in vegetation increases. Future uses of this method for understanding landscape management in residential landscapes are discussed.
\end{abstract}

Keywords: Foreclosure, Landsat, NDVI, Landscape Management, Urban Remote Sensing 


\section{Introduction}

Over 10 million U.S. homeowners submitted foreclosure filings during the foreclosure crisis between 2007 and 2012, mostly in urban areas (RealtyTrac 2014). Many neighborhoods achieved peak foreclosure rates in 2009, with as many as one in every five homes foreclosed upon in some neighborhoods (RealtyTrac 2012). Numerous studies have investigated the geography of foreclosure in different locales and at different scales (e.g. Schafran 2013; Perkins 2008; Yanmei 2011). This work contributes to that tradition by examining the relationship between foreclosure and land cover change in Maricopa County, Arizona. Understanding the drivers of land use and land cover change is a fundamental goal in geography and it is especially important to do this in urban systems, which are dynamic and affected by social, economic and ecological drivers.

The volume of properties affected by foreclosure over the past decade suggests the potential for dramatic change in vegetation cover driven by changes in lawn management. There is anecdotal evidence of vegetation change in light of high foreclosure rates and images of overgrown or barren property are common (Schilling 2009). However, it does not appear that prior studies have attempted to quantify the effect of foreclosure on vegetation and determine the extent to which vegetation changes on individual foreclosed properties are ubiquitous and inevitable or dependent on neighborhood, and city-level intervention dynamics.

Identifying whether parcel-level lawn management changes are coincident with foreclosure relies on the ability to isolate foreclosure from other drivers of neighborhood vegetation patterns. These drivers include (a) urban form, (b) landscape aesthetic, and (c) spillover due to other changes in the neighborhood and (d) weather and climate conditions. First, the cover and greenness of lawns and other residential vegetation (hereafter lawn status) is dependent on urban form and development style, which varies across time period and has resulted in changes in the density of houses and the amount of outdoor space in each lot (Atkinson-Palombo 2010). In this definition, high lawn status is not necessarily the same as a high-status lawn. Rather, it is an area with a high NDVI value in relation to other nearby yard spaces. Second, lawn status depends on landscaping aesthetics. Vegetation growth depends on initial landscaping practices. Grasses are 
more sensitive to management changes than trees and larger shrubs (Pouyat et al. 2009). Additionally, the prevalence of grass as a proportion of yard space varies depending on the landscaping aesthetic developed on the property. Other covers, such as trees, bare ground, or pavement contribute to both differences in initial lawn status and the degree to which the lawn can change. In Maricopa County, yard vegetation ranges from xeric landscaping - which requires less water and does not include grass - to mesic landscaping - which often includes summer and winter grasses as well as many leafy tree species (Martin et al 2003). Third, land cover outcomes may change due to the social dimensions of the economic crisis itself, through which spillover effects have changed the prices of nearby homes (Ihlanfeldt and Mayock 2014, Lin et al 2009, Leonard and Murdoch 2009) and willingness to pay for environmental amenities (Cho et al. 2011). Many homeowners associations (HOA) lost significant revenue during the foreclosure crises (especially those that weren't yet at $100 \%$ build out) and many responded by cutting back on services and landscaping requirements (Perkins 2009). Last, the timing of climate events such as rain and extreme heat may influence lawn status, although the level of compensation to these events with increased irrigation varies across census tracts in accordance neighborhood norms like lot size, the prevalence of mesic landscaping and the income levels of the residents (Balling et al. 2008). Disentangling these complexities suggests the need to examine changes in lawn status using a dataset that can capture the spatio-temporal heterogeneity of the urban landscape at the scale of a parcel.

Non-judicial foreclosures are the most common type of foreclosure in Arizona and are well documented in the public record, making them amenable to study (Thompson 2010; Fidelity National Title Agency 2014). When a homeowner stops making payments on their mortgage and goes into default, the lender can file a notice of sale (NOS) with the county to auction the house to a new owner. An auction would be scheduled no earlier than 91 days after the NOS, and three things could happen: (1) the borrower repays the debt amassed through missed payments and penalties and the auction is canceled; (2) the property receives no acceptable bids and becomes a Real Estate Owned (REO) until the lender sells it on the open market. (3) the auction results in a sale followed by a title transfer when paid in full; the original occupant is evicted (if they had not already moved out). 
While foreclosure is a clearly documented process, existing documentation does not indicate what physically happened on properties in the periods before or after foreclosure that may have resulted in a change in level of property maintenance. There is a need to develop a technique to quantify vegetation change associated with foreclosures, as they are broadly dispersed through time and space, occur at the scale of a parcel, and are subject to complex contextual differences. Remote sensing data, particularly imagery from long-term continuity missions such as the Landsat program, can provide insight into parcel-level lawn changes over multi-decadal time periods, with an approximately 16 day sample frequency. Remotely-sensed data has been used extensively in urban areas for photogrammetry, landscape classification and macro-level statistical analysis (e.g. Jensen and Cowen 1999; Wilson and Brown 2015; Blaschke 2010). Previous work on land cover classification (Wentz et al 2014) is especially relevant to the research in this paper, although attempts to identify temporally and spatially dispersed sub-pixel changes in land cover appear to be rare. The Normalized Difference Vegetation Index (NDVI) has been used with macro-level analysis of urban vegetation (for examples see Guhathakurta and Gober 2007; Buyantuyev and Wu 2009; Turner and Ibes 2011) although Mesev (2011, 156-157) notes that micro-level urban classification with remote sensing yields tenuous results and temporal lags between structure and function reduce the validity of static classifications. Therefore, there is a need to develop methods that are more temporally sensitive.

Here, we examine changes in the Normalized Difference Vegetation Index (NDVI) derived from a time series of Landsat imagery collected over the period of 2002 to 2012. NDVI is a normalized ratio of reflected near infrared (NIR) light, which is related to the height and total area of vegetation, and red light, which is related to health (or "greenness") of the vegetation, and is calculated as:

$$
\mathrm{NDVI}=(\mathrm{NIR}-\mathrm{Red}) /(\mathrm{NIR}+\mathrm{Red})
$$

Decreasing lawn management in arid systems such as Maricopa County is hypothesized to lead first to the red reflectance increasing as the photosynthetic pathways break down (the plant is unable to absorb red light for photosynthesis), and subsequently in a decreasing NIR reflectance 
as the internal leaf structure breaks down through decomposition. Thus, as plants begin to dry up and decompose, NDVI is expected to decrease. Vegetative cover/NDVI patterns are particularly pronounced in desert landscapes when turf grass is introduced and must be maintained in the arid climate.

To address these challenges, we developed a technique to quantify small-scale ecological phenomena, like vegetation change associated with foreclosure, that are broadly dispersed through time and space and subject to complex contextual differences. Our study aims to do this in a way that bridges applied studies of the geography of foreclosure (e.g. Zhang and Leonard 2014; Ihlanfeldt and Mayock 2014; Kaplan and Sommers 2009) with studies of humanenvironment interactions that focus on the ecological consequences of yard care choices (e.g. Nassauer et al. 2009; Fraser et al. 2013; Polsky et al 2014).

\section{Methods}

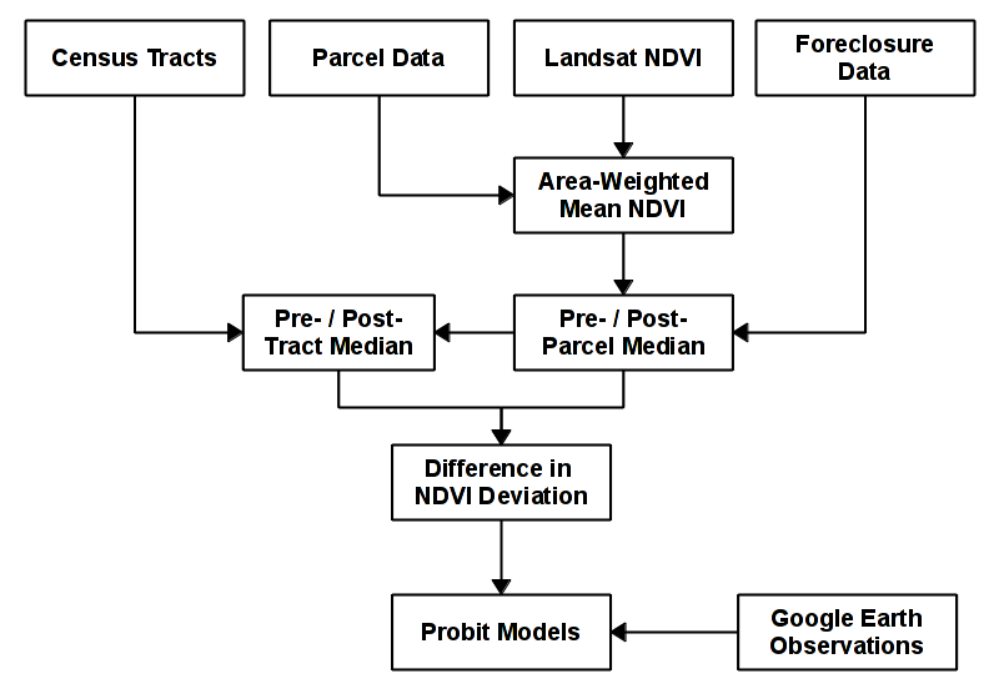

Figure 1: Data Flow Chart 


\subsection{Study area description}

Our analysis focused on Maricopa County, Arizona from 2002 to 2012. Maricopa County is located in south central Arizona and was home to around four million residents in 2012, 90\% of whom lived in the urban area surrounding Phoenix, which itself had a population of approximately 1.5 million residents (USCB 2014). The population of the county has quadrupled over the past 50 years and doubled in the past 25 years (USCB 2014, ADOA-EPS 2014). In 2013 there were approximately 1.2 million residential parcels in the county, defined as single-family detached homes and condominiums (MCAO 2013). This number excludes commercial multitenant rental properties (MCAO 2013).

The character of parcels in the county varies widely. Most residential parcels are under $30 \mathrm{~m}^{2}$. Houses on average occupy $28 \%$ of the area on each parcel, although the standard deviation of $23 \%$ demonstrates the wide range of potential lawn area (The Information Market 2013). Many homeowners and communities have adapted to the climate with low-management practices which reduce the vegetated area that can be affected by foreclosure and any associated landscape management changes.

The foreclosures analyzed were those that passed through non-judicial foreclosure, or Trustee's Sale, as outlined in the introduction. During the study period, $28 \%$ of all residential parcels passed through at least one foreclosure (The Information Market, 2013). The county was a significant beneficiary of the housing bubble in the early 2000s and victim of the bubble implosion, with foreclosures skyrocketing after 2007 (The Information Market 2013). The analysis period of 2002 to 2012 was chosen to cover the start of the housing bubble and the reduction in foreclosure rates following the crash. As of January 2015, the foreclosure rate in Maricopa County had dropped to a level of around one foreclosure per 797 homes per month (RealtyTrac 2015), although it was still above the levels seen during the bubble, as shown in Figure 2. 


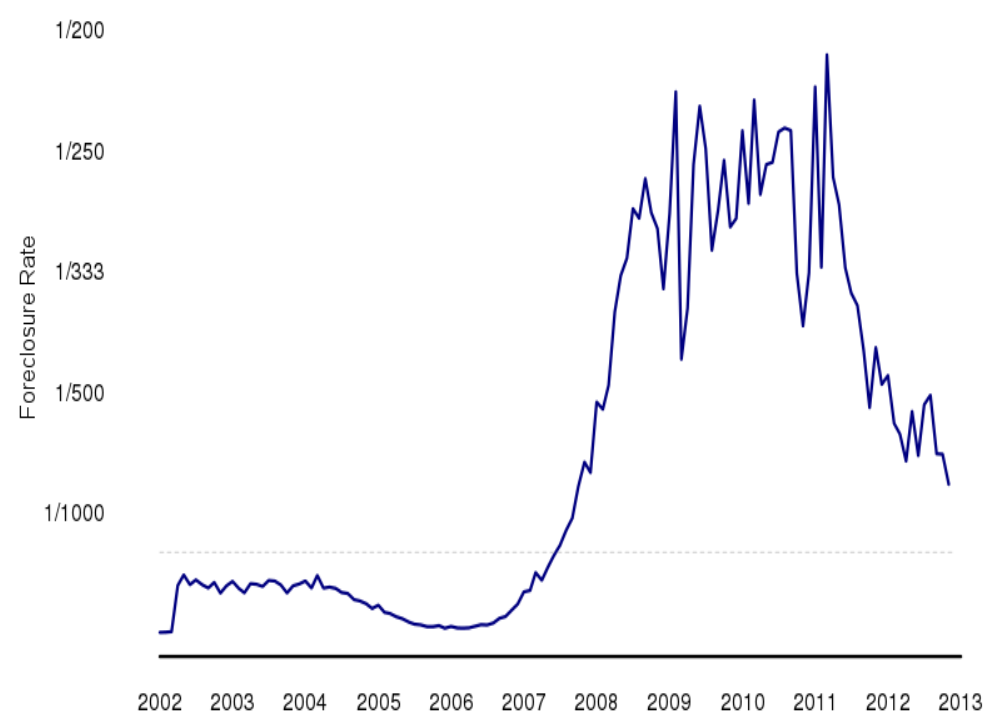

Figure 2: Maricopa County Monthly Foreclosure Rate: 2002-2012

(The Information Market 2013)

Phoenix has built a reputation as an "oasis in the desert" (Larsen and Swanbrow 2006) and has never faced mandatory water restrictions (Gober and Trapido-Lurie 2006; Redman and Kinzig 2008). As such, per capita residential water use of around 409 liters per day is close to the national average despite the arid climate (Kenny and Juracek 2012; Santos 2013). Climate and its effect on evapotranspiration drive high levels of outdoor water use (Wentz and Gober, 2007), and much of domestic water use goes to support vegetation that would not be able to survive if reliant only on the $182 \mathrm{~mm}$ of rain that typically fall in a single year, given the average high temperature in July is 41.2 C (National Weather Service 2015).

\subsection{Review of Key Data Sets}

\subsubsection{Landsat NDVI}

For this analysis we used Landsat path 37, row 37, which covered 95\% of the county's residential parcels. The Landsat series of sensors captures biweekly imagery (approximately 26 images per year) at $30 \mathrm{~m}^{2}$ resolution, and have a historical archive dating back to approximately 1984 from 
which NDVI can be calculated. We used Landsat Five Thematic Mapper (TM) data for the period 4 January 2002 through 4 November 2011 and Landsat Seven Enhanced Thematic Mapper Plus (ETM+) data for the period 12 January 2002 through 31 January 2012 that was downloaded from the USGS EarthExplorer website.

The data set consisted of 438 radiometrically-corrected images. Landsat path 37, row 37 covered Maricopa county with the exception of the sparsely populated southwest corner. The fmask raster (Zhu and Woodcock 2012) provided with the Landsat multispectral data permitted masking of cloud-covered areas. Some data was also missing from the Landsat Seven scenes due to the scanline-corrector (SLC) problem, which results in a loss of around $22 \%$ of the pixels within any given scene (USGS 2013). Because the two satellite systems provided interleaved 16-day passes, no attempt was made to interpolate missing data within individual scenes. For each scene, we calculated NDVI.

\subsubsection{Census Data}

2013 TIGER/Line shapefiles for census tract boundaries in Maricopa were downloaded from the United States Census Bureau website.

\subsubsection{Parcel Data}

We used the Maricopa County Assessor's Office 2013 parcel database shapefile representing all 1,545,616 residential and non-residential parcels, joined with the entries in their 2013 ST 42030 Residential Master Data Table to create a spatial database of 1,214,578 residential parcels in the county.

\subsubsection{Foreclosure Data}

We acquired a residential foreclosure database from a commercial vendor (The Information Market, 2013) covering NOS for the period 2002-2012. The database contained 462,380 records, representing 341,983 distinct parcels or approximately $28 \%$ of the $1,214,578$ residential parcels documented by the Maricopa County Assessor's Office (2013). Of the foreclosure records, 
242,638 (52\% of total records) indicated a completed foreclosure (Trustee's Deed or TD), representing 232,266 distinct parcels or 19\% of total number of residential parcels as of 2013 .

\subsection{Data Cleaning and Processing}

Of the 232,266 distinct parcels in the foreclosure records, 226,706 had entries in the Assessor's residential data file and associated parcel shapefile. The 809 parcels foreclosed within the first year of a home's existence (based on the construction year in the county data set) were excluded under the assumption that the one-year pre-foreclosure period would not reflect owner-initiated landscape management practices and would overlap with prior parcel land use (often high-NDVI agriculture) that was not considered relevant to this analysis. An additional 71,896 parcels were excluded because the one-year pre-/post-foreclosure window extended into the period before or after the 2002-2012 analysis period. An additional 13 parcels were excluded because of inadequate NDVI data due to location on the margins of the Landsat scenes or because of the aforementioned masking. This left 153,988 parcels for analysis.

\subsubsection{Area-Weighted Mean NDVI}

Landsat data has a moderate temporal and spatial resolution that makes it possible to compare vegetation before and after a parcel is foreclosed. However, the small size of many residential parcels (under the $30 \mathrm{~m}^{2}$ Landsat pixel size) and differences in initial vegetation complicates the direct use of Landsat data and NDVI to assess vegetation. Pixels are not aligned on parcel boundaries, multiple pixels can be affected by a single parcel and multiple parcels can be covered by a single pixel, diluting the measured NDVI change associated with sub-pixel sized additions or removal of vegetation. The LEDAPS orthorectification of the Landsat data reduces the average geolocation error to \pm 1 pixel ( \pm 30 meters) (Thomas et al 2011), leaving the possibility that the pixels associated with some small parcels can actually be covering adjacent small parcels in some time-series scenes. In addition, small parcels are commonly covered by large houses, leaving only fringes of potential lawn area (Robbins and Birkenholtz 2003) around the edges of these parcels, limiting the amount of area where vegetation can be added or removed, and constraining the practical range of NDVI change. 
To account for some of these challenges, parcel NDVI was calculated by taking an area-weighted mean of the values of pixels that covered each parcel. This parcel-centric algorithmic approach addressed the weaknesses of using conventional statistical sub-pixel classification techniques (such as those used by Yang et al 2003) with foreclosure events that were sparsely distributed across time and space. Pixels that did not have a centroid within a residential parcel were masked in order to mitigate distortions from potential pixel overlaps with public green spaces and agricultural land.

\subsubsection{Pre-Post Parcel Median}

For each individual parcel, the median NDVI was taken of all available scenes in the period both one year prior to the foreclosure auction and one year following. This interval was chosen in order to encompass the typical 240 days needed to complete a foreclosure (O'Donnell 2013) and a comparable post-foreclosure period, and to control for the annual phenological cycle. NDVI medians were used rather than means to mitigate distortion from transients caused by brief climate events, or errors in individual Landsat scenes caused by misregistration or cloud cover.

\subsubsection{Pre-Post Tract Median}

Normative NDVI was defined as the median NDVI for all parcels in the census tract containing the queried parcel, excluding any parcels that ever went into foreclosure. Norms were calculated during the pre-foreclosure and post-foreclosure periods defined above, which yielded pre/post norms specific to each foreclosure incident. Use of tract median as a norm controlled for confounding social or weather conditions.

\subsection{Difference in Deviations Calculation}

The before and after medians were compared with before and after medians for the normative NDVI to obtain pre-foreclosure deviation and a post-foreclosure deviations as shown in figure 3. The differences between the pre-foreclosure deviations and post-foreclosure NDVI deviations were then used to determine the direction and magnitude of foreclosure-coincident lawn status 
change. A negative difference indicated a potential decrease in lawn status, while a positive difference indicated a potential increase in lawn status. The magnitude of the NDVI differences represented the magnitude of change in vegetation, which was hypothesized to correlate with the potential that a lawn status change occurred.

While fully understanding the social and ecological factors that might lead to the diversity of landscaping changes to foreclosure is beyond the scope of this paper. The methodology developed in the paper is specific to semi-arid environments, and would not be directly applicable in more-temperate climates. While unmanaged turf grass can be expected to wither in the Arizona Summer sun (lower NDVI), it could be expected to grow tall in areas with plentiful rainfall (slightly higher NDVI).

We illustrate the technique by highlighting results for two foreclosed parcels. Figure 3 shows an example visualization of analysis for a single parcel in Tempe. The tract norm for this 2-acre parcel is stable over the displayed period, whereas the median parcel NDVI showed an obvious change after the foreclosure auction on May of 2009. By contrast, figure 4 shows a parcel in Mesa where NDVI was quite low and there was little obvious change before and after the foreclosure in May of 2010.

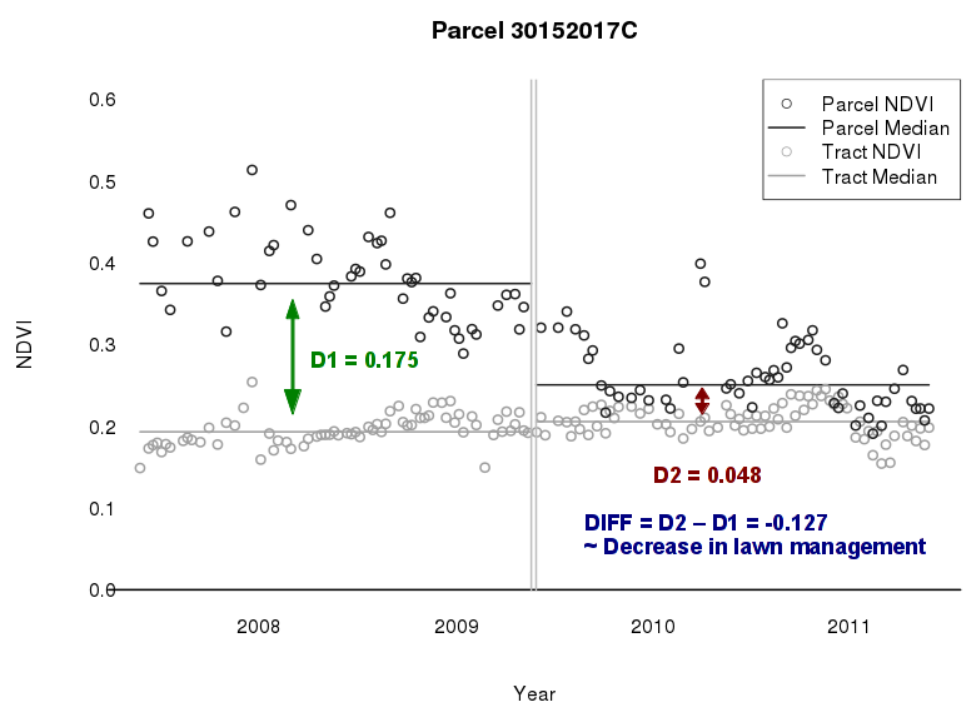


Figure 3: Example Parcel with NDVI Change

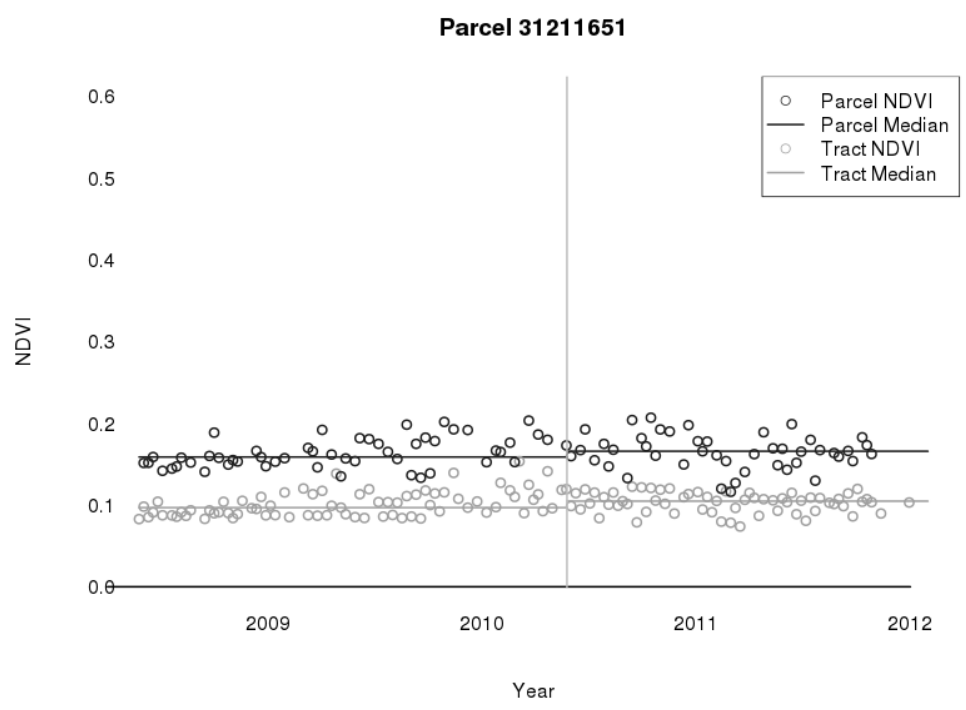

Figure 4: Example Parcel with No Change

\subsection{Validation}

To identify parcels where lawn status change appeared to coincide with foreclosure, we analyzed historical high-resolution imagery available through Google Earth to compare pre- and postforeclosure vegetation. A random sample of 100 parcels was weighted based on the magnitude of the z-score of the difference in NDVI deviation. This strategy allowed us to sample the parcels in the long tails of the normal distribution of the differences in deviation adequately. We anticipated the tails would correspond with the most significant change in vegetation. This method of sampling provided an inverse normal sampling distribution that captured more of the parcels with potential change than an unweighted random sample (Griffin and Hauser 1993; Long 1997).

Historical imagery for each sampled parcel was observed in Google Earth by three independent research assistants and coded as positive change, negative change, or no change. Observations were also coded as high, medium and low certainty based on the spatial resolution, color contrast, 
and temporal availability of imagery. Conflicting interpretations were resolved by majority. Changes in vegetation were coded positive or negative based on observed additions or removal of managed vegetation, regardless of size. Mixed changes (such as removal of turfgrass and addition of desert plants in xeric landscaping) were coded as positive or negative based on the whether a greater area of change was estimated to be positive or negative. Transient changes in vegetation that appeared to be related solely to climate events (based on similar changes on surrounding parcels), or appeared to be caused by maturation of vegetation unrelated to observable management change (like the growth of trees in yards that exhibited no other changes) were coded as no change.

A second random sample of 100 non-foreclosed parcels with randomly-selected event dates was processed as a control group using the same procedure.

\subsection{Probit Regression Model}

We used probit models to calculate the probability that parcel difference in NDVI deviation values underwent foreclosure-coincident changes in lawn status based on visual inspection of Google Earth images. Separate models estimated the probability that of observing "positive change" (as opposed to no change or negative change) and "negative change" (as opposed to no change or positive change). The probability curves were then multiplied by the difference in deviation z-scores to provide estimates of the number of parcels that underwent foreclosurecoincident change in lawn status.

\section{Results}

Foreclosure events were spatially and temporally diffuse. Even at the height of the foreclosure crisis in 2009, the median nearest-neighbor distance between parcels undergoing foreclosure within the same month was around 250 meters, in contrast to the median nearest-neighbor distance between all parcels of 20 meters (figure 5). This spatio-temporal dispersion made it difficult to analyze foreclosure-coincident lawn status change in terms of aggregated clusters (Greenberg et al 2014), necessitating analysis at the parcel scale. 


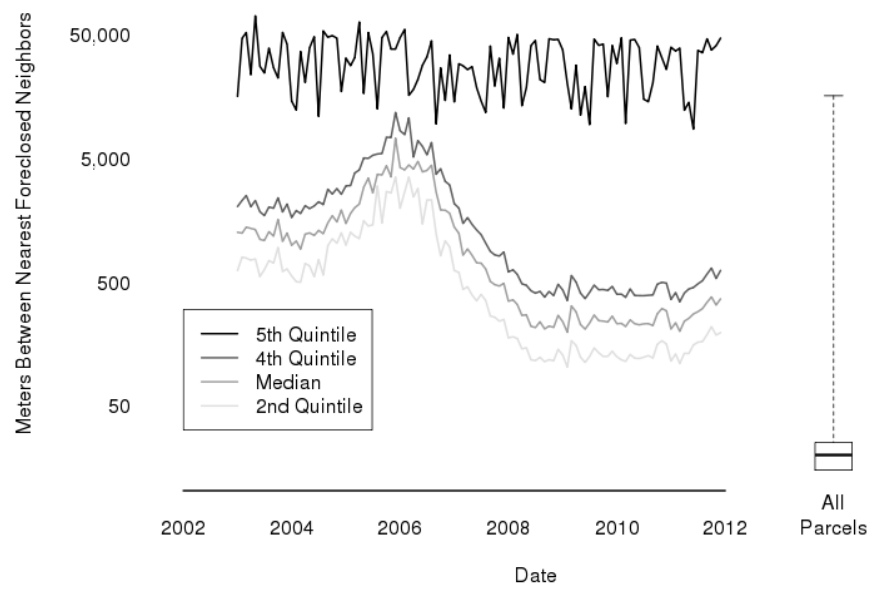

Figure 5: Nearest-Neighbor Analysis of Foreclosed Parcels by Month 2002-2011

Most parcels had little change in NDVI coincident with foreclosure, indicating that foreclosure did not usually result in large declines in vegetation. The overall distribution of differences for the analyzed foreclosure events shown in figure 6 was a normal curve with a mean that was slightly negative (-0.002), indicating a slight NDVI decrease associated with foreclosure. However, the standard deviation of 0.01 indicated that $99.7 \%$ of all events were within a \pm 0.03 NDVI deviation, which is only $3 \%$ of the practical NDVI range of zero to one, or $8 \%$ of the aforementioned typical NDVI range of 0.4 between vegetated and non-vegetated surfaces. Therefore, from a macro viewpoint, lawn status changes coincident with foreclosure had a minimal effect on overall vegetation or resource usage in Maricopa County. 


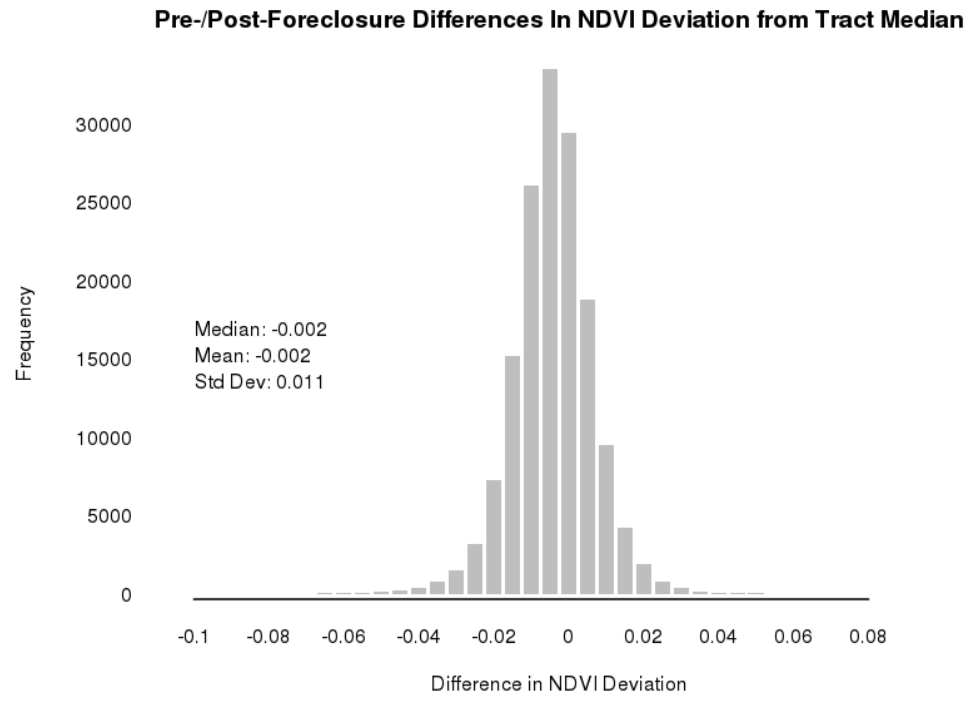

Figure 6: Aggregate Distribution of Foreclosure-coincidental Deviations from Tract Norms

However, visual coding of sampled foreclosed parcels using Google Earth historical imagery before and after foreclosure indicated that observable changes in lawn status sometimes occurred. The fitted probit models (figure 7) indicated that increases in NDVI difference in deviation resulted in decreases in the probability of decreased lawn status and increases in the probability of increased lawn status. Multiplication of the probit models by the parcel differences in NDVI deviation resulted in an estimate that 28,000 foreclosed parcels underwent observable declines in lawn status from 2002-2012. A slightly smaller 14,000 foreclosed parcels were estimated to have increases in lawn status that coincided with foreclosure.

Similar coding for the non-foreclosed random control group (figure 8) revealed far fewer observations of negative lawn status change, which indicates an increased probability of decreased lawn status associated with foreclosure. 


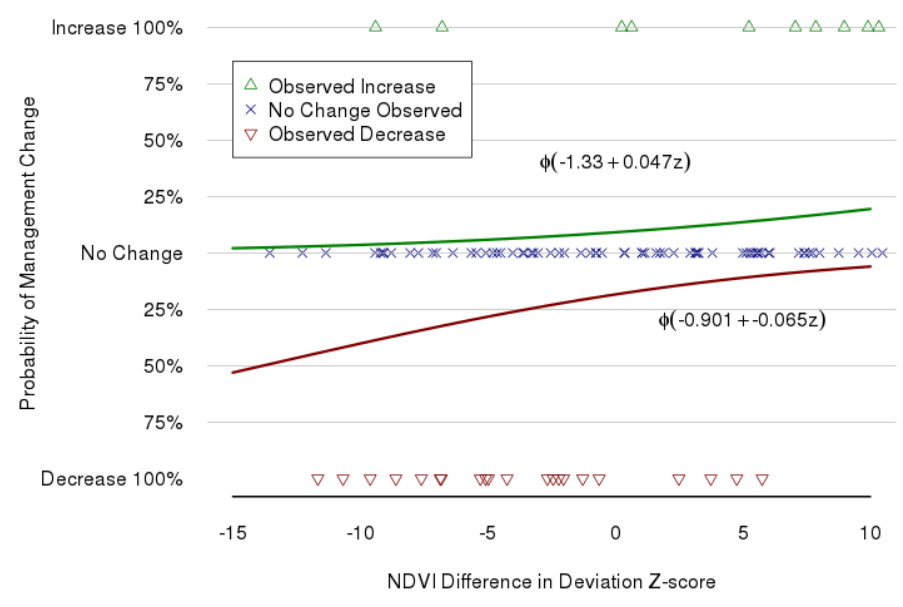

Figure 7: Probability Modeling of Landscape Management Change on Foreclosed Parcels From Sampled Google Earth Observations

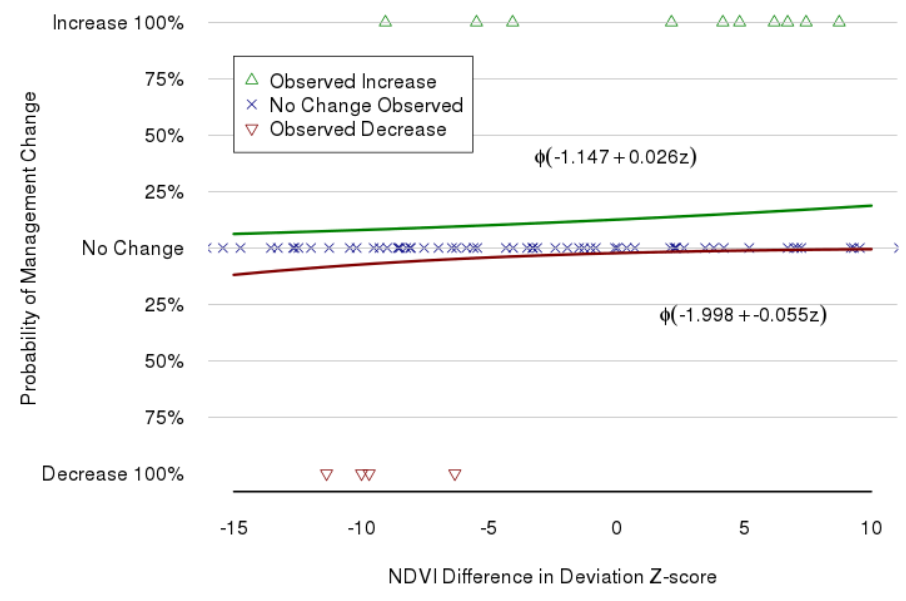

Figure 8: Probability Modeling of Landscape Management Change on All Parcels From Sampled Google Earth Observations 


\section{Discussion}

The difference in deviation analysis developed in this paper assesses parcel changes in NDVI after controlling for the influence of (a) urban form, (b) landscape aesthetic, and (c) spillover due to other changes in the neighborhood and (d) weather and climate conditions. Based on validation using Google Earth images and probit regression models, we conclude that most individual foreclosures in Maricopa County did not lead to observable changes in lawn status. However, the difference in deviation method is a successful way to identify changes in lawn status. The presence of thousands of parcels that did experience post-foreclosure vegetation change suggests the need for investigation into the factors that define those specific places and times, and whether analysis of those characteristics can be generalized to answer broader questions about foreclosure and/or urban ecology.

Although the method may be useful to work in other cities, researchers should consider the context of foreclosure and climate when they interpret results. The deviation of differences methodology is based on the specific dynamics of foreclosure in Maricopa County, which did not result in widespread demolition of homes (Schuetz et al 2015) and where water inputs are required to maintain lawns due to the arid environment. In cities like Detroit, Michigan or Cleveland, Ohio, foreclosure is frequently a prelude to abandonment and demolition (Griswold et al 2014) and rainfall is more abundant. Additionally, the City of Cleveland, $\mathrm{OH}$ has instituted a policy to mow vacant lots and properties (City of Cleveland 2015). Both of these activities could change the direction of NDVI change expected to follow if regular maintenance stops.

The methodology we present identifies coincident vegetation change and therefore the structure of causation will require grounded theoretical work to address ontological questions. For instance, understanding how landscape changes should be related to the social disruptions and transitions that sometimes accompany foreclosure. Current theory cannot guide decisions about whether management changes associated with preferences of new owners should be attributed to foreclosure, and whether transient changes associated brief periods of foreclosure-related vacancy should be considered significant. 
A broader objective of this research was to address the challenge of using urban remote sensing to analyze small-scale ecological phenomena that have broad temporal and spatial dispersion. Uncertainties associated with data quality and availability were addressed by generating probabilistic rather than categorical outputs. We believe this simple but novel application of remote sensing represents a meaningful contribution that may prove valuable for analysis of other sparse, temporally-distributed urban ecological phenomena. While applied to foreclosure, it may also be a useful tool for examining other phenomenon that create tensions between drivers of residential landscape management. The recent water restrictions in California, for example, have highlighted the potential for nuisance property ordinances and water use restrictions to be ni conflict (e.g Horsemen 2015).

The results of this study raises the question of what forces kept existing management practices in place on most parcels, and whether this indicates a resilient system where behavioral and institutional factors are critical. From the perspective of urban ecology theory, this raises the question of whether persistence in mesic lots indicates a maladaptive but path dependent system, much in line with field studies of lawn management and residential landscape preferences (e.g. Polsky et al. 2014). The failure of foreclosure to modify vegetation in a universal and detectable way suggests that many of the institutions that work beyond the household may play a strong and disparate role in modulating the degree to which foreclosure results in ecological change. This suggests that foreclosure, a temporally and spatially explicit opportunity for management change, may provide a useful experiment for the emerging ecological homogenization hypothesis, that surmises that cities are becoming more ecological similar to one another over time (Polsky et al. 2014). For instance, homeowner's associations are very common in Maricopa County (Turner and Ibes 2011), many suppress the impact of foreclosure on yard vegetation when foreclosure are low and the income base for property management provided by other residents allows it. As foreclosure increases and revenues decline, there may be fewer opportunities for management. Understanding the space-time nature of foreclosure filing information is likely to be an important component of analysis building from the dependent variable we have constructed. 


\section{Acknowledgements}

This material is based upon work supported by the University of Illinois Campus Research Board, and the USDA through ILLU-875-919. Any opinions, findings and conclusions or recommendations expressed in this material are those of the authors and do not necessarily reflect the view s of United States Department of Agriculture. Data for this project is archived at the Central Arizona-Phoenix Long-Term Ecological Research Program, which is supported by the National Science Foundation.

\section{Bibliography}

Arizona Department of Administration - Employment and Population Statistics (ADOA-EPS). (2014). Data, research and analysis on Arizona's population.

https://population.az.gov/population-projections (accessed 24 September 2014).

Atkinson-Palombo, C. (2010). New housing construction in Phoenix: Evidence of "new suburbanism?" Cities 27 (2), 77-86.

Balling, R.C., Gober, P., \& Jones, N. (2008). Sensitivity of residential water consumption to variations in climate: An intraurban analysis of Phoenix, Arizona. Water Resources Research 44 (10), W10401. doi:10.1029/2007WR006722.

Blaschke, T. (2010). Object based image analysis for remote sensing. ISPRS Journal of Photogrammetry and Remote Sensing 65 (1), 2-16.

Buyantuyev, A. \& Wu, J. (2009). Urbanization alters spatiotemporal patterns of ecosystem primary production: A case study of the Phoenix metropolitan region, USA. Journal of Arid Environments 73 (4-5), 512-520. 
Cho, S-H., Kim, S.G., \& Roberts, R.K. (2011). Values of environmental landscape amenities during the 2000-2006 real estate boom and subsequent 2008 recession. Journal of Environmental Planning and Management 54 (1), 71-91

City of Cleveland. (2015). Vacant property and lot maintenance service. http://webapp.clevelandoh.gov/aspnet/docs/get.aspx ?id=726\&file=VacantPropertyCleanUp.pdf (accessed 15 April 2015).

Fidelity National Title Agency. (2014). Foreclosure FAQ.

http://www.fntarizona.com/foreclosure-faq/ (accessed 18 November 2014).

Fraser, J.C., Bazuin, J.T., Band, L.E., \& Grove, J.M. (2013). Covenants, cohesion, and community: The effects of neighborhood governance on lawn fertilization. Landscape and Urban Planning 115, 30-38.

Gober, P. \& Trapido-Lurie, B. (2006). Metropolitan Phoenix: Place Making and Community Building in the Desert. Philadelphia, PA: University of Pennsylvania Press.

Greenberg, J.A., Cutts, B.B., Fraterrigo, J.M., Miller, J., Pavlovic, N., \& Minn, M. (2014). Quantifying foreclosure effects on land cover using remotely sensed data. Presented at the 99th Annual Meeting of the Ecological Society of America, Sacramento, CA, 12 August.

Griffin, A. \& Hauser, J.R. (1993). The voice of the customer. Marketing Science 12 (1), 1-27.

Griswold, N.G., Calnin, B., Schramm, M., Anselin, L., Boehnlein, P. (2014). Estimating the Effect of Demolishing Distressed Structures in Cleveland, OH, 2009-2013: Impacts on Real Estate Equity and Mortgage-foreclosure. Cleveland, $\mathrm{OH}$ : The Center on Urban Poverty and Community Development, Case Western Reserve University. http://blog.case.edu/msass/2014/02/26/FinalReportwithExecSummary_modified.pdf (accessed 26 April 2015).

Guhathakurta, S. \& Gober, P. (2007). The impact of the Phoenix urban heat island on residential water use. Journal of the American Planning Association 73 (3), 317-329. 
Horseman, J. (2015, April 8). Drought: Bill would legalize brown lawns. The Press Enterprise. http://www.pe.com/articles/brown-764234-water-bill.html (accessed 28 April 2015)

The Information Market. (2013). Foreclosure database (proprietary data). http://theinformationmarket.com.

Ihlanfeldt, K. \& Mayock, T. (2014). The variance in foreclosure spillovers across neighborhood types. Public Finance Review 5 June, 1-30.

Jensen, J.R. \& Cowen, D.C. (1999). Remote sensing of urban/suburban infrastructure and socioeconomic attributes. Photogrammetric Engineering and Remote Sensing 65, 611-622.

Kaplan, D.H. \& Sommers, G.G. (2009). An analysis of the relationship between housing foreclosures, lending practices, and neighborhood ecology: Evidence from a distressed county. The Professional Geographer 61 (1): 101-120.

Kenny, J.F. \& Juracek, K.E. (2012). Description of 2005-10 Domestic Water Use for Selected U.S. Cities and Guidance for Estimating Domestic Water Use, Scientific Investigations Report 2012-5163. Washington, DC: United States Geological Survey. http://pubs.usgs.gov/sir/2012/5163/sir12_5163.pdf (accessed 12 February 2015)

Larsen, L. \& Swanbrow, L. (2006). Postcards of Phoenix: Images of Desert Ambivalence and Homogeneity. Landscape Journal 25 (2), 205-217.

Larson, K.L, Hall, S.J. Cook, E.M., Funke, B., Strawhacker, C.A., \& Turner, V.K. (2008). Social-Ecological Dynamics of Residential Landscapes: Human Drivers of Management Practices and Ecological Structure in an Urban Ecosystem Context. The Final Report from an IGERT/SOS Graduate Workshop, Central Arizona Project Long Term Ecological Research (CAP LTER) Arizona State University. 
Leonard, T. \& Murdoch, J.C. (2009). The neighborhood effects of foreclosure. Journal of Geographical Systems 11 (4), 317-332.

Lin, Z., Rosenblatt, E., \& Yao, V.W. (2009). Spillover Effects of Foreclosures on Neighborhood Property Values. The Journal of Real Estate Finance and Economics 38 (4), 387-407

Long, J.S. (2007). Regression Models for Categorical and Limited Dependent Variables. Thousand Oaks, CA: SAGE Publications.

Maricopa County Assessor's Office (MCAO). (2013). Shape File and ST 42030 Residential Master Data File. http://mcassessor.maricopa.gov/reports-data-sales/data-sales/data-policiespricing/ (accessed 17 September 2014).

Martin, C.A., Peterson, K.A., \& Stabler, L.B. (2003). Residential landscaping in Phoenix, Arizona, U.S.: Practices and preferences relative to covenants, codes, and restrictions. Journal of Arboriculture 29 (1), 9-17.

Mesev, V. (2011). Exploring the temporal lag between the structure and function of urban areas. In Urban Remote Sensing: Monitoring, Synthesis and Modeling in the Urban Environment, Yang, X., Ed. Wiley-Blackwell: West Sussex, UK, 2011; 155-162.

Nassauer, J.I., Cooper, D.A., Marshall, L.L., Currie, W.S., Hutchins, M., \& Brown, D.G. (2014). Parcel size related to household behaviors affecting carbon storage in exurban residential landscapes. Landscape and Urban Planning 129, 55-64

National Weather Service. (2015). Phoenix, AZ: NOAA Online Weather Data. http://www.weather.gov/climate/xmacis.php?wfo=psr (accessed 12 February 2015).

O’Donnell, K. (2013). Report: Foreclosure filings in Arizona at lowest level since 2006. Cronkite News 6 November. http://cronkitenewsonline.com/2013/11/report-foreclosure-filings-in-arizonaat-lowest-level-since-2006/ (accessed 22 November 2014). 
Perkins, K. L. (2008). The geography of foreclosure in Contra Costa county, California. Doctoral dissertation, University of California, Berkeley.

Perkins, C. (2009) Privatopia in distress: The impact of the foreclosures crisis on homeowners' associations. Nevada Law Journal 10, 561-585.

Polsky, C., Grove, J.M. Knudson, C., Groffman, P.M., Bettez, N., Cavender-Bares, J., Hall, S.J., Heffernan, J.B., Hobbie, S.E., Larson, K.L, Morse, J.L., Neill, C., Nelson, K.C., Ogden, L.A., O’Neil-Dunne, J., Pataki, D.E., Chowdhury, R.R., \& Steele, M.K. (2014). Assessing the homogenization of urban land management with an application to US residential lawn care.

Proceedings of the National Academy of Sciences 111 (12), 4432-4437.

Pouyat, R.V., Yesilonis, I.D., Golubiewski, N.E. (2009). A comparison of soil organic carbon stocks between residential turf grass and native soil. Urban Ecosystems 12 (1), 45-62.

RealtyTrac. (2012). Foreclosure Real Estate Listings. http://www.realtytrac.com/home/ (accessed October 28, 2012).

RealtyTrac. (2014). Phoenix Real Estate Statistics and Foreclosure Trends Summary. http://www.realtytrac.com/statsandtrends/az/maricopa-county/phoenix (accessed 18 November 2014).

RealtyTrac. (2015). Maricopa County Real Estate Trends and Market Info. http://www.realtytrac.com/statsandtrends/foreclosuretrends/az/maricopa-county (accessed 15 February 2015).

Redman, C.L., \& Kinzig, A.P. (2008). Water can flow uphill: A narrative of Central Arizona. In Agrarian Landscapes in Transition: Comparisons of Long-Term Ecological and Cultural Change. Oxford and New York: Oxford University Press. 
Robbins, P. \& Birkenholtz, T. (2003). Turfgrass revolution: measuring the expansion of the American lawn. Land Use Policy 20 (2), 181-194.

Santos, F. (2013). An arid Arizona city manages its thirst. New York Times 16 June.

http://www.nytimes.com/2013/06/17/us/an-arid-arizona-city-manages-its-thirst.html (accessed 12 February 2015).

Schilling, J. (2009). Code enforcement and community stabilization: The forgotten first responders to vacant and foreclosed homes. Albany Government Law Review 2, 101-163.

Schafran, A. (2013). Origins of an urban crisis: The restructuring of the San Francisco bay area and the geography of foreclosure. International Journal of Urban and Regional Research 37 (2), 663-688.

Schuetz, J., Spader, J.S., Cortes, A. (2015). Have Distressed Neighborhoods Recovered? Evidence from the Neighborhood Stabilization Program. Social Science Research Network http://ssrn.com/abstract=2573814 (accessed 26 April 2015).

Thomas, N.E., Huang, C. Goward, S.N., Powell, S., Rishmawi, K., Schleeweis, K., \& Hinds, A. (2011). Validation of North American Forest Disturbance dynamics derived from Landsat time series stacks. Remote Sensing of Environment 115 (1), 19-32.

Thompson, J. (2010). The Foreclosure Process in Arizona. http://www.phoenixrealestateguy.com/the-foreclosure-process-in-arizona-with-spiffy-graphic/ (accessed 12 February 2015).

Turner, V.K. \& Ibes, D.C. (2011). The Impact of Homeowners Associations on Residential Water Demand Management in Phoenix, Arizona. Urban Geography 32 (8), 1167-1188.

United States Geological Survey (USGS). (2013). SLC-off Products: Background. http://landsat.usgs.gov/products_slcoffbackground.php (accessed 18 November 2014). 
United States Census Bureau (USCB). (2014). Population.

http://www.census.gov/topics/population.html (accessed 24 September 2014).

Wentz, E., \& Gober, P. (2007). Determinants of small-area water consumption for the city of Phoenix, Arizona. Water Resources Management 21 (11), 1849-1863.

Wentz, E.A., Anderson, S., Fragkias, M., Netzband, M., Mesev, V., Myint, S.W., Quattrochi, D, Rahman, A. \& Seto, K.C.. (2014). Supporting global environmental change research: A review of trends and knowledge gaps in urban remote sensing. Remote Sensing 6(5), 3879-3905.

Wilson, C.R. \& Brown, D.G. (2015). Change in visible impervious surface area in southeastern Michigan before and after the "Great Recession:" Spatial differentiation in remotely sensed landcover dynamics. Population and Environment 36, 331-355.

Yang, L., Xian, G., Klaver, J.M., \& Deal, B. (2003). Urban land-cover change detection through sub-pixel imperviousness mapping using remotely sensed data. Photogrammetric Engineering and Remote Sensing 69 (9), 1003-1010.

Yanmei, L. I. (2011). Geography of opportunity and residential mortgage foreclosure: A spatial analysis of a US housing market. Journal of Urban and Regional Analysis 3(2), 195-214.

Zhang, L., \& Leonard, T. (2014). Neighborhood impact of foreclosure: A quantile regression approach. Regional Science and Urban Economics 48, 133-143.

Zhu, Z., \& Woodcock, C.E. (2012). Object-based cloud and cloud shadow detection in Landsat imagery. Remote Sensing of Environment 118 (15), 83-94. 